\title{
Environmental Literacy Assessment: Exploring the Potential for the Assessment of Environmental Education/Programs in Ontario Schools
}

\author{
Igbokwe, A. Blessing \\ University of Windsor, ON, Canada
}

\begin{abstract}
Environmental education (EE) initiatives and programs are continually being introduced to schools and school boards in Ontario. For example, the EcoSchools program was initiated in 2002 and has seen a great increase in school participation since its inception. Several schools and school boards have adopted these initiatives with claims and praises on their effectiveness for improving students' learning, environmental literacy and the school's physical environment. However, the aggregate and quantifiable effect of these programs on students' environmental knowledge and literacy is usually not emphasized. This paper is the report of a work in progress and proposes an environmental literacy assessment for elementary and secondary schools in south western Ontario as a tool for assessing the effectiveness of EE initiatives.
\end{abstract}

\section{Introduction}

Environmental education (EE) initiatives and programs are continually being introduced to schools and school boards in Ontario. For example, the EcoSchools program was initiated in 2002 and has seen a great increase in school participation since its inception. Several schools and school boards have adopted these initiatives with claims and praises on their effectiveness for improving students' learning, environmental literacy and school's physical environment [27]. However, the aggregate and quantifiable effect of these programs on students' environmental knowledge and literacy is usually not emphasized notwithstanding the fact that the EcoSchools program states among its' goals the development of ecological literacy for K-12 students. In the light of this, there is a need for standardized EE assessment, accountability and an unbiased third party evaluation of the effectiveness of EE programs in against the pontifical claims by the program developers that their initiatives are making positive difference in the teaching of $\mathrm{EE}$ and increasing environmental literacy among students. Furthermore, there are limited studies and baseline reference on students' EE achievement in K-12 in Ontario schools. This makes it difficult to state with confidence the degree to which the EE programs are impacting students' environmental literacy.

Environmental educators in Canada have constantly called for the prioritization of EE in Canada and Ontario schools [2], [45]. consequently, it is not surprising to see that within the last five years, Ontario has seen a surge in EE initiatives and programs in response to calls for the prioritization of EE in Canadian schools. Few of these programs, like the EcoSchools and EarthCARE ${ }^{\mathrm{TM}}$ have gained tremendous recognition and are continually being introduced to school boards and schools to provide strategies for curriculum-compliant resources and activity-based learning in $\mathrm{EE}$ in order to assist students in developing environmental literacy at the same time engage in practices to become environmentally responsible citizens [11]. The EcoSchools program was created in 2002 with 13 schools in one school board but currently has 909 schools in 32 school boards in the 2008/2009 school year. The program has seen an astronomical increase of $6892 \%$ since its inception and currently, over 540 schools in Ontario have been certified as EcoSchools [1]. In addition, the EarthCARE ${ }^{\mathrm{TM}}$ environmental program created by the Ottawa-Carleton District School Board has seen its' own increase with 96\% of the 146 schools currently participating. Several schools and school boards that have adopted these initiatives have claimed and praised the programs' effectiveness for improving students' learning and the school's physical environment. Participating schools are assessed and evaluated for success using indicators like energy conservation, and waste minimization among certified schools. These yardsticks, notwithstanding are developed by the program creator. Increased number of schools participating and the endorsement of EcoSchools program in 2007 by Council of Education Directors [27] is also deemed as an indicator of the program's success. The above evaluation excludes the assessment of students' environmental literacy as pertains to knowledge gained by students and their environmental attitude in response to the program.

There are visible evidence of the EcoSchools program success in terms of energy efficiency tracked by using the Waste Minimization and Energy Conservation Standards and improved school infrastructure achieved through the school yard greening activities [27]. School infrastructure improvement is measurable but there is little or no documentation on students' environmental literacy assessment or formal literacy evaluation of the EcoSchools program in terms of meeting its' objectives of improving environmental literacy.

Although some form of assessment and evaluation takes place in the EcoSchools and EarthCARE ${ }^{\mathrm{TM}}$ programs, notwithstanding, assessments tabling students' successes as well as the impact of the program on environmental literacy have not been documented.

\section{Definition of Terms}

A number of terms used in this paper form the foundation for this report (for example, environment, EL and EE). Therefore, the definitions of these terms have been included in this section. 


\subsection{Environmental Initiative/Programs}

EE initiatives and programs in this paper will refer to all proposals, plans, projects, unique teaching processes, act or statement designed to address environmental concern or issue, or projects adopted to assist in educating students on environmental matters and fostering EL. Two major initiatives often referred to in this paper are the EcoSchools and the EarthCARE ${ }^{\mathrm{TM}}$ programs, developed by school boards in Ontario.

\subsection{Environment}

When EE is discussed, it is pertinent to clarify the meaning of one of its root words, environment. The word environment suggests different things to various groups or scholars, due to its complexity and the multiple perspectives through which it may be viewed. Several definitions are proffered for the word environment. The picture of outdoors and nature quickly comes to mind when the word environmental is mentioned, but environment connotes more than the outdoors and nature although these two components are parts of it.

According to Brennan and Withgott [47], the word environment is from the French environner meaning to surround. It is the sum total of our surroundings that include all of the abiotic factors (nonliving things) and the biotic factors (living things) that include the built environment and all the human-made urban cities. While considering the environment in its most inclusive sense, Brennan and Withgott highlight that it "consists of the complex web of scientific, ethical, political, economical, and social relations that shape our daily lives” (p. 3). Similar to Brennan and Withgott's definition is that proffered by Raven and Berg [31]. They defined the environment as "all the external conditions, both abiotic and biotic, that affect an organism or group of organisms” (p. G7). Botkin and Keller [3] defined it as "all factors (living and nonliving) that actually affect an individual organism or population at any point in the life cycle". It could sometimes be used "to denote a certain set of circumstances surrounding a particular occurrence” (p. G6).

Interestingly, from all the definitions, a pattern begins to emerge. It can be deduced that the environment can be either a tangible or an intangible phenomenon, sometimes palpable yet insubstantial at times. Also deducible from these definitions is the fact that the environment is complex and comprise a sets of systems that interacts with and influences one another. Another interesting trajectory in the definition of the environment is that as living beings, humans dwell within an environment.

From the definition of the word environment, the apparent emerging themes on what the environment includes are:

1. The built environment that includes constructed surroundings that provide the setting for human activity which ranges from the large-scale civic surroundings to the personal places;

2. The biophysical environment which comprises the physical and biological factors along with their chemical interactions that affect an organism; and

3. The environmental systems that include the surroundings of a physical system (political, economic and cultural systems) that may interact with the system by exchanging mass, energy, or other properties

\subsection{Environmental Education}

$\mathrm{EE}$ is a contested field and there is no unity or agreement on one definition [10]. According to Russell, Bell and Fawcett [36], “approaches and definitions of environmental education vary by culture, reflecting diverse relationships to their environment" (p. 198). Definitions are influenced by philosophical approaches and the various ways of conceptualising EE also "offer a basis for understanding difference of opinion as to what environmental education should be in practice" ( [10], p. 30).

Some definitions of EE tend to emphasize the goals or outcomes of EE. For example, Stapp et al.[38] defined EE as "aimed at producing citizenry that is knowledgeable concerning the biophysical environment and its associated problems, aware of how to help solve these problems, and motivated to work toward their solution” (p. 34), while other definitions focus on the description, for example, Disinger [10] focused on the dimensions of EE. Notwithstanding the lens through which the definition of $\mathrm{EE}$ is conceived, all $\mathrm{EE}$ should recognise the "importance of viewing the environment within the context of human influence, incorporating an examination of economics, culture, political structure, and social equity as well as natural processes and systems" ([26], p. 1).

For the purpose of this report paper, the definition of EE offered by the Working Group on Environmental Education [45] in their report is utilised. This definition presents some dimensions for EE in Ontario schools, and provides some foundation situated within the framework of the Ontario school curriculum and thus very relevant in the context of this research report. In this light, EE as defined in the Report of the Working Group on Environmental Education is:

Education about the environment, for the environment, and in the environment that promotes an understanding of, rich and active experience in, and an appreciation for the dynamic interactions of:

- The Earth's physical and biological systems

- The dependency of our social and economic systems on these natural systems

- The scientific and human dimensions of environmental issues

- $\quad$ The positive and negative consequences, both intended and unintended, of the interactions between human-created and natural systems. (p. 6)

\subsection{Environmental Literacy (EL)}

Similar to the contention in the definition of EE, there is also a contention with regards to the definition of EL. However, there is a consensus among researchers that EL is an outcome of EE or EE programs and initiatives [22], [26], [37], [45], [41] and a fundamental goal of EE [8].

Roth [33], defined EL as "essentially the capacity to perceive, interpret the relative health of the environmental systems and take appropriate action to maintain, restore, or improve the health of those systems” (p. 10). While this definition is also true of EL, it does lack some of the elements in the definition of the environment. For example, 
the political, emotional and cultural aspects that are also a crucial part of the environment plus emphasis on the connection between nature and culture are missing. Orr in his definition of ecological literacy, referred to it as "a quality of mind that seeks out connections ... a broad understanding of how people and societies relate to natural systems, and how they might do so sustainably” (pp. 3-4). Being environmentally literate also presumes "an awareness of the interrelatedness of life and knowledge of how the world works as a physical system” (p.3). Furthermore, to be environmentally literate implies that we understand our place within the environment and as part of the environment, the dependency of our (human) health and survival on the environment, the magnitude, and rate of population change, species extinction, soil loss, deforestation, desertification, climate change, ozone depletion and other environmental issues that face the earth. Finally, EL also connotes "practical competence" (p. 3), competence in skills and knowledge required for making responsible environmental decisions.

\subsection{EL Assessment}

Assessment can be defined from either the data gathering or diagnostic perspectives [19]. In this paper, EL assessment connotes a formal data gathering in the area of EE and a combination of this data to reach an overall judgement. For the purpose of this report, EL assessment will serve as both a diagnostic and a data gathering process useful for making overall judgement on program effectiveness and for determining baseline knowledge of participants.

\section{Literature review}

Environmental educators in Canada have called for the prioritization of EE in Canadian schools for the past 40 years [2], [30], [45].

While a number of countries have made significant advancements towards the implementation of EE programs, progress have remained slow in secondary schools, with too few teachers and professors having adequate training in ecology or multidisciplinary teaching styles [14]. Within the last decade, there has been an increase in the use of EE programs (for example; the EcoSchools and EarthCARE ${ }^{\mathrm{TM}}$ programs) in Ontario schools [12], [27]. Statistics from the EcoSchools program website indicated that there are currently over 1,000 schools in 40 different school boards across Ontario already using the EcoSchools Program [27]. The EarthCARE ${ }^{\mathrm{TM}} 2010$ end of year report on the progress of the EarthCARE ${ }^{\mathrm{TM}}$ program in the Hastings and Prince Edward District School claimed that $98 \%$ of schools in this school board are already involved in the EarthCARE ${ }^{\mathrm{TM}}$ program. Similarly, the 2010 end-of-year report by the Ottawa-Carleton District School Board, another school board embracing this program, indicate that $90 \%$ of the schools in this district are also involved in EarthCARE ${ }^{\mathrm{TM}}$.

Although the use of EE programs (especially the EcoSchools and EarthCARE ${ }^{\mathrm{TM}}$ programs) in Ontario schools is on the rise in elementary and secondary schools, some have argued programs such as EcoSchools and EarthCARE $^{\mathrm{TM}}$, designed to be infused with other schools subjects, may not really be effective for achieving EL in students. Arguments against this format of delivery is that infusion may lack the "sequential order for developing ecological literacy within individual courses and from grade to grade" and become "thinly spread out into other subjects" thereby causing EE to lose its unique identity. This form of implementation, as critiqued by Puk and Behm [30], "translates into unfocussed curriculum and the unfulfilled establishment of knowledge base” (p.227). Puk and Behm argued that the infusion model of EE is not working for Ontario secondary schools. On the other hand, the EcoSchools and EarthCARE ${ }^{\mathrm{TM}}$ programs claim that their initiatives have been very successful in involving students and improving environmental practices and behaviour. The past Minister of Education, Kathleen Wynne's statement, praise the initiative by saying that children are already leaders in caring for the earth and how proud she is that the classrooms are supporting environmental literacy across Ontario [28].

In addition, several schools and school boards in Ontario who have embraced the EcoSchool and EarthCARE ${ }^{\mathrm{TM}}$ initiatives offer high praise on the program's effectiveness for improving students' learning, EL and the school's physical environment [27]. This success is further echoed in the news media with students' activities taking centre stage, for example: 'Eco-clubs make the grade with Green' [13]; 'Halton's EcoSchool program thriving: Environmental program has grown from four to 99 schools since 2006' [37]. It is evident that these headlines focus generally on school participation, which in itself is not bad, but nonetheless fails to highlight the Ontario Ministry of Education standards for EE which stresses the effective EE goes beyond participation; but provides "opportunities for learners to become environmentally literate; to apply their acquired knowledge, perspectives, skills, and practices in real world situations; and to become environmentally responsible citizens who are aware of the global implications of local action” (p. X).

As highlighted in the Tbilisi Declaration [40], the goals of EE are:

Fostering clear awareness of, and concerns about economic, social, political and ecological interdependence in urban and rural areas; to provide every person with opportunities to acquire the knowledge, values, attitudes, commitment and skills needed to protect and improve the environment; to create new patterns of behaviour of individuals, groups and society as a whole towards the environment (p. 15).

The Declaration also highlights the categories of EE objectives:

Awareness - to help social groups and individuals acquire an awareness and sensitivity to the total environment and its allied problems.

Knowledge - to help social groups and individuals gain a variety of experience in, and acquire a basic understanding of the environment and its associated problems.

Attitudes - to help social groups and individuals acquire a set of values and feelings of concern for the environment and the motivation for actively participating in environmental improvement and protection.

Skills - to help social groups and individuals acquire the skills for identifying and solving environmental problems. 
Participation - to provide social groups and individuals with an opportunity to be actively involved at all levels in working toward resolution of environmental problems. (p. 15)

From the earlier definition of EL and EE, EL is an outcome of EE. These outcomes can (has been) measured using observable constructs (knowledge/awareness, attitudes, skills and participation). Studies on the assessment of EL have recognised several observable constructs of EE learning domains encompassed in EE goals. These constructs are outlined below:

Ecological or environmental knowledge/indigenous ecological specie knowledge, affective disposition, cognitive skills, values, attitudes, motivation, participation, commitment - verbal and actual, environmental behaviour, environmental involvement, and environmental sensitivity [7], [18], [19], [34], [39].

These constructs are usually of interest to studies that measure EL. These constructs are numerous and distinguishable, at the same time, the boundary between them are blurry.

Under knowledge, the foundational knowledge of ecological concepts and principles, knowledge of environmental problem and problem-solving and action strategies and issues associated with them, knowledge in the social sciences which include history, physical and cultural geography, political science, sociology, psychology and economics are considered the foundation knowledge outcome of EE (19].

According to Marcinkowski [19], cognitive skills include "skills for investigating environmental problems and issues, including identification, analysis, and evaluation; and skills for dealing with action strategies, including their appropriate selection and planning, implementation, and evaluation of discrete action". Marcinkowski recognised the affective skills as reflective of "valuing, organising values into system, integrating values into a world view of ethics, and acting according to these” (p. 168)

Attitude and values where students examine personal values, wants and need pertaining to the natural environment have been grouped as one by Marcinkowski [19]. Marcinkowski categorises affective dispositions of EE under environmental sensitivity, a set of values, a feeling of attitude of concern, and the motivation to actively participate in environmental improvement. According to Marcinkowski, attitude is commonly assessed among these categories.

The components of EL, as highlighted above, form the basic framework for EL assessment instrument design.

\subsection{Environmental Education Programs}

Organizations and schools are developing several strategies and creative ideas for teaching class and schoolwide EE. School environmental initiatives like The EarthCARE $^{\mathrm{TM}}$, Classroom Earth, Environment as an Integrating Context for Learning Program -The EIC Model $^{\mathrm{TM}}$, Outdoor Education, Eco Regeneration Field Study, EcoSchools, Green School Program, Environmental Club, Go Green Initiatives, School Yard Greening, and Tree Planting are just a few examples of EE programs that have been undertaken in the past or currently practiced. These initiatives, aimed at the study or protection of the environment, all have goals focused around gaining or raising environmental awareness and developing EL in students.

In North America (for example, USA), the Go Green initiative (GGI) continues to grow as governments become key initiators of 'green' buildings. Schools can either earn a gold, silver or bronze certificate under the US Green Building Council's LEED (Leadership in Energy and Environmental Design) certification system.

In response to the state and need of EE in Ontario, the Ministry of Education included new environmental science courses to give priority to EE (Ontario Ministry of Education, 2008). In addition, several EE programs and initiatives are also used to address the need of EE in Ontario schools. Ontario school boards currently embrace two major EE programs. In the wake of the recommendation of the Report of the Working Group on Environmental Education [45] calling for the support of school boards in their efforts to develop board-wide framework for EE which would reflect the board's culture and that of its community and partners (p. 12), EE initiatives in Ontario (especially the EcoSchools and EarthCARE ${ }^{\mathrm{TM}}$ programs) have garnered province-wide acceptance. An increasing number of elementary and secondary schools are adapting them as a means of injecting meaningful EE into the school's curriculum and engaging students in responsible environmental behaviour. School environmental initiatives, however, are characterized by differential levels of success and effectiveness. In Ontario, the EarthCARE ${ }^{\mathrm{TM}}$ and EcoSchools programs have been particularly successful in the sense that there has been a wide acceptance, and a steady increase in the number of schools participating in these programs, although the success of the programs in developing environmentally literate students is yet to be documented.

Notwithstanding outward appearance and state-of-theart environmentally sensitive buildings emphasized in these programs, which in itself is an excellent and a great starting point for EE in schools, it is not enough on its own to achieve a well rounded EE. 'Green school' in its real sense should include solidification of its EE achievement, enriching EE content and fortifying the potential to improve the effectiveness of EE in schools.

\subsection{The EarthCARE ${ }^{\mathrm{TM}}$ Program}

The EarthCARETM program can be considered as one of the leading EE Initiatives in Ontario schools, based on the number of schools utilising it. The EarthCARE ${ }^{\mathrm{TM}}$ program, initiated by the Ottawa-Carleton District School Board in Ontario, Canada, is custom made to meet the need of the school district. The EarthCARE ${ }^{\mathrm{TM}}$ program has been referred to as a unique environmental program that offers curriculum-compliant resources and activity-based learning. The eight objectives of the program include: avoiding wasted energy costs (5-10\% of total utility costs) through increased conservation behaviours and efforts; positioning the board as an educational leader and innovator in the sustainability movement; creating a culture of environmental stewardship and action that encourages and supports a safe learning environment; improving the efficiency of building operations through training in preventive maintenance and new systems; adding value to the program with high quality, cross-curricular EE resources and strategies; engaging diverse learning communities around a common focus 
(environmental sustainability) and providing shared activities to bring these community together; enhancing fiscal health by providing a strategy and a program that convert wasted expenditures into program and organizational renewal. From 2008 to 2009, the EarthCARE $^{\mathrm{TM}}$ program saved the Ottawa-Carleton and Hastings/Prince Edward boards over \$2 million and reduced $\mathrm{CO}_{2}$ emissions by over 19 tonnes [11].

\subsection{EcoSchools Program}

The EcoSchools program, similar in aim to the EarthCARE $^{\mathrm{TM}}$ program, is an EE program in Ontario for grades K-12. It aims at helping the students develop ecological literacy while engaging in practices that help them become environmentally responsible citizens. Developed and run by school boards, the Ontario EcoSchools program also aims to help improve school building operations in order to reduce environmental impacts and overall energy consumption. The program, developed in 2002, addresses environmental issues and provides EE program that can be used by the whole province of Ontario.

The program provides resources and environmental perspective for the choices in operating schools and in planning classroom programs based on the Ontario Curriculum. It is aligned with all the goals and strategies of the framework for EE in Ontario [29]. All EcoSchools participating schools and school boards try to reflect the goals and strategies outlined in the Ministry of Education's framework for EE. The EcoSchool program claims that their most important goal is to involve the students in EE and ecological literacy. The program has developed a comprehensive guide for schools to use in order to reduce their energy use, minimize waste, design school buildings and grounds to reduce non-renewable energy use and encourage sustainability, greater participation in environmental initiatives and student leadership (p. X).

With its' certification process, the EcoSchools program recognises schools for their environmental initiatives, innovations and achievements by awarding either a bronze, silver of gold status to schools depending on how well the school has met the requirements of the program which include four main components: ecological literacy, waste minimization, energy conservation and schoolground greening. The Ontario EcoSchools program helps schools and school boards achieve these objectives by: promoting ecological literacy for all students with teaching resources linked to the Ontario curriculum; providing opportunity for leadership for students through the establishment of EcoTeam; establishing environmentally sound operational practices through the adaptation of the Ontario EcoSchools templates for use throughout the board; developing a continual process for improvement in EE and operational practices within each school through the initial and followup EcoReviews; incorporating an EE component into the school planning process through the creation of a boardlevel environmental committee; providing an opportunity for the whole school community to work together to develop environmentally-responsible practices at school through the Action Plan templates; and benchmarking their environmental practices, assessing their progress and recognizing their achievements through an annual certification process.
While there is visible evidence of the EcoSchools program success in terms of energy efficiency tracked by using the Waste Minimization and Energy Conservation Standards and improved school infrastructure achieved through the schoolyard greening activities and measurable school infrastructure improvement, there is little or no evidence on students' environmental literacy assessment or any formal EL assessment.

\subsection{Summary of Previous Studies on EL Assessment}

Very limited studies have documented the assessment of EE literacy in Ontario or even Canada as a whole; nevertheless, there is substantive evidence of EL assessment and evaluation in the USA and around the world. Studies assessing EL could fall under any of the following categories:

The first category are studies assessing the effectiveness of EE programs for fostering EL or assessment of EL as an outcome of EE programs and initiatives [7], [34], [35], [44]. These studies measure the change in EL components (knowledge, attitudes, behaviour, skills or awareness) that occurred following a short period of exposure to an EE course or program. The results of these studies generally suggest an improvement in environmental knowledge, attitude and behaviour. These findings are corroborated by Hart and Nolan's [15] findings in their critical analysis of EE research. Nolan and Hart observed that in most cases, "the environment-related experience was found to have a positive effect on knowledge, attitude and predisposition to action or responsible environmental behaviour” ([15], p. 7). They also noted that although "attitudes of concern about the environment appear to be increasing” (p. 8), there is little understanding about what this [increase in attitude] implies.

The second category are studies done to assess EL or establish EL baseline of students or teachers [22], [39].

The third category is studies on EL Assessment conducted to determine the relationship between EL components as predictors of responsible environmental behaviour - REB [16].

The fourth category is studies conducted to assess EL in order to develop or test the validity, reliability and usability of an instrument for measuring EL [20], [23]. A number of useable EL instruments have been developed, for example, the Middle School Environmental Literacy Instrument (MSELI).

Some of these studies fall comfortably under more than one group listed above. Studies assessing the effectiveness of EE programs for fostering EL or assessment of EL as an outcome of EE programs, and studies done to determine EL or establish an EL baseline data utilised several variables or components of EL. Program evaluation assessment using EL utilized fewer components than studies done to determine students' EL. However, in every study, environmental or ecological knowledge is one of the variables assessed. The inclusion of other EL variables changes in accordance to the goal of the assessment. From the literature, the common groups of components of EL variables utilised in major assessments are:

- Knowledge, awareness, attitude and participation [39]. 
- Knowledge, environmental issue awareness, knowledge of skill, and evaluation of environmental issues [7].

- Knowledge, skills, affect and behaviour [9].

- $\quad$ Awareness, knowledge, attitude, skills and participation [17], [40].

- Cognitive knowledge, affect, cognitive skills, and behaviour [22].

Although no rule of thumb exists in determining what EL component to include, McBeth and Volk stated that common features in EL framework include reflection of at "least four of the Tbilisi categories of objectives, namely knowledge, affect, skills, and participation (i.e., behaviour);” (p. 56) and addressing at least three major thematic emphases apparent across the history of EE within the country. As stated earlier, none of these components is monolithic. Notwithstanding the combination of variables chosen to be assessed, the exclusion of one component does not necessarily signify non-assessment as components are intricately linked and a clean line of separation cannot be drawn between them.

Methodologies employed in these researches varied. The three broad groups of research methodologies were utilized: quantitative [22], [39], qualitative [32] and mixed methods [34]. Quantitative methods were the most common methods used. The least common methodology was qualitative methods. A good number of studies employed a mixing of both methods. The advantages of mixing methods in EL assessment was extolled by various researchers, and mixed methods was commended as being capable of providing a methodological completeness [35]. However, in studies involving large samples from a relatively large population which require extensive statistical analysis and aims to generalise findings to the population, quantitative methodology was usually employed [21].

\subsection{Formulating a Conceptual Framework}

In order to assess EL, it is important to appropriate a tool that encompasses all aspects of EE and the basic guidelines for teaching EE. To this respect, several scholars [24], [39], have developed instruments for assessing EL either at the elementary, secondary or college level. Meanwhile, EE researchers (see [7]) have used already existing instruments to assess EL for EE programs.

Assessing EL can be a complex event since EL can include several components [44]. The Tbilisi declaration stated the objectives of EE as: awareness, knowledge, attitudes, skills and participation [40]. These initial concepts of EE have been expanded and developed to a framework that steer the development of EE curricula in a manner that would be consistent with guiding principles established at Tbilisi [17]. The framework includes four goal levels for EE curriculum, these goals include; ecological foundations, conceptual awareness - issues and values, investigation and evaluation, and environmental action skills - training and application. Therefore, in order to ensure content validity of assessment and evaluation tool, chosen or developed instruments will have to include these four levels of EE goals.

\section{Statement of purpose}

The main purpose of this research will include:

1. Determine the level of student involvement in these programs.

2. Assessing the impact of EE programs on students' EL in Ontario schools (with major focus on the EcoSchools and EarthCARE programs).

\subsection{Research Questions}

Based on the issues raised in the literature review, and in order to achieve the above purpose, this research will explore and try to proffer answers to the following questions;

1. What is Ontario students' level of EL?

2. What is the level of participation of Ontario students in EE programs

3. Do major EE initiatives have an impact on Ontario students EL?

\section{Navigating Methodology}

To navigate the various methodologies available in education and EE research and contemplate the most efficient and effective way to approach an EL assessment research, it is necessary to ponder the words of Russell, Bell and Fawcett [36]:

Many currents stir and animate the waters of Canadian environmental education. We travellers [EE researchers] must pick and choose among them, depending on the vantage points we seek, the pace we deem desirable, and the destination we have in mind. The routes we wish to follow are seldom direct. They twist and turn while currents far more powerful than our canoes carry us along. Choices must be made....There is no single correct way of proceeding and what we propose now is simply to pause for a moment to contemplate some of the directions that lie ahead. (p. 203).

The quote shines a light on the various approaches that can be utilised in an EL assessment research. True to the quote above, there is no one correct way of proceeding and in choosing a specific research path, one moves further away from the paths not taken. Generally, a chosen methodology will most likely be informed by the research objectives and to some extent, the researcher's preferences.

Although EL can be assessed using qualitative, quantitative or mixed methods [34], [35], the quantitative research approach resonates for large scale studies and for studies that are intended for use in making further generalisation. Quantitative methodology is an approach that is used for "explaining phenomena by collecting numerical data that are analysed using mathematical methods (in particular statistics)" ([25], p. 1). In assessing EE, the use of a quantitative approach is particularly attractive as it lends itself to the utilisation of a large sample, which in turn may give greater credibility to any generalisations that might be made from the results. 


\section{Conclusion}

The increasing number of schools participating in EE programs in Ontario is very commendable. It may be argued that these initiatives are new and constitute a major leap for schools in Ontario in terms of injecting EE into the school curriculum so they may not merit a rigorous assessment for now. However, assessment can highlight the level at which the students are, and shine a light of what may be lacking in terms of students' knowledge, attitudes, skills and environmental awareness. This can lead to improvement and changes where necessary. To ensure accountability, the effectiveness of EE in Ontario schools needs to be measured both on a system level and against clearly defined student achievement outcomes [45]

In light of the absence of a baseline study on K-12 EL in Ontario, a research that assesses EL and EL outcomes as a product of initiatives will provide a baseline reference on Ontario students' EL competence. A study of this nature will also assist EE program designers such as the EcoSchools and EarthCARE ${ }^{\mathrm{TM}}$ team to effectively assess their programs, adapt and modify them over time in response to feedback gotten from students' literacy level. Finally, a study of this nature will assist policy makers in concretizing the importance of establishing a properly coordinated and long term sustainable EE assessment program. With this information, policy makers can make adjustments and improvements based on areas where students have shown deficiencies.

Assessment of outcomes of EE efforts in terms of students' achievement is an issue that is of paramount importance in EE [45]. EL, considered a major outcome of $\mathrm{EE}$, is a fundamental goal of EE [8], [22], [41], [45]. Students are expected to "acquire knowledge, skills, and perspectives that foster understanding of their fundamental connections to each other, to the world around them, and to all living things” ([29, p. 11). Assessing EL can provide information for the field of EE in Ontario to "evaluate its progress and make decisions related to future direction" ([42], p 73) or any needed improvement in programs.

To further highlight the place of EL assessment in EE, the Tbilisi declaration, one of the foremost documents of EE, called for the assessment of content, literacy and programs in EE "in order to encourage and improve them and to extend them to other educational institutions and programmes" ([41], p. 21). Other studies have reiterated the need for assessment and evaluation of EL as part of the agenda for EE [22].

In the Report of the Working Group on Environmental Education [45], accountability in the form of measuring the effectiveness of EE against clearly defined student achievement outcomes is one of the intended results and vision for EE in Ontario. This report considers EL an important product of any form of EE in schools. The development and implementation of transparent mechanism and other assessment tools for monitoring student achievement in EE apart from report cards was among the final recommendations of this report.

In response to the incessant plea by environmental educators to include EE in all aspects of Canada's education system, EE programs and initiatives in elementary and secondary schools have seen a rise within the last five years. EcoSchools and EarthCARE ${ }^{\mathrm{TM}}$ programs are two of the most popular of these initiatives adopted by schools and school boards to address the need for the inclusion of EE in Canadian schools. While the EcoSchools and the EarthCARE $^{\mathrm{TM}}$ programs use their own criteria for assessing and evaluating the success of their programs, formal EL assessment is still not being employed, and programs have no baseline study to refer to in terms of the improvement they have made in creating environmentally literate citizens.

The notion of assessing EL is relatively new when compared to the number of years EE has taken the centre stage [43]. Available studies that document the assessment of EL are focused on the United States and other parts of the world while in Canada, similar studies that document Canadian students' EL is almost non-existent.

The availability of limited studies and baseline reference on students' EL for K-12 in Ontario make it difficult to state with confidence the degree of impact the EE programs are having in terms of improving students' EL. In light of the absence of a baseline data on K-12 EL in Ontario, providing a baseline reference on Ontario students' EL is of paramount importance.

This paper is an initial partial report of a thesis work in progress, but it is envisioned that the final results may indicate a significant relationship between students' environmental literacy and schools engaged in the EcoSchools and the EarthCARE ${ }^{\mathrm{TM}}$ initiatives. This conclusion is backed up by other studies that have documented EL as an outcome of EE programs and initiatives [7], [34].

This conclusion may also be considered too simplistic since environmental literacy can also be influenced by other factors that the researcher hopes to unravel when this thesis is concluded.

\section{References}

1] Anonymous. (April 21, 2009). Ontario greens over 1,000 schools, leading to over 5,500 jobs. Canada NewsWire. Retrieved July 18, 2010, from CBCA Reference and Current Events. (Document ID: 1682721791).

[2] Beckford, C. L. (2008). Re-Orienting environmental education in teacher education programs in Ontario. Journal of Teaching and Learning, 5(2), 55 - 66.

[3] Botkin, D.B. \& Keller, E.A. (2003). Environmental science: Earth as a living planet. $4^{\text {th }}$ Ed. Danver, MA: John Willey.

[4] Brennan, S. \& Withgott's, J. (2005). Essential environment: The science behind the stories. San Francisco, CA: Pearson and Benjamin Cummings.

[5] Chu, H., Lee, E. A., Ko, H. E., Dong, H. S., Lee, M. N., Min, B.M. \& Kang, K, H. (2007). Korean year 3 children's environmental literacy: A prerequisite for a Korean environmental education curriculum. International Journal of Science Education, 29(6), 731-746.

[6] Culen, G.R. (2005). The status of environmental education with respect to the goal of responsible citizenship behavior. In H.R. Hungerford, W.J. Bluhm, T.L. Volk \& J.M. Ramsey (Eds.), Essential readings in environmental education, 3ed. (pp. 37-45). Champaign, IL: Stipe Publishing.

[7] Culen, G.R. \& Moni, P.R.S. (2003) Assessing environmental literacy in a nonformal youth program. Journal of Environmental Education, 34(4), 26-28. 
[8] Cutter-Mackenzie, A. \& Smith, R. (2003). Ecological literacy: the 'missing paradigm' in environmental education (part one). Environmental Education Research, 9(4), 497-524.

[9] Disinger, J.F. (1997) Environment in the K-12 curriculum: An overview. In R.J. Wilke (Ed.), Environmental education teacher resource handbook (pp. 23-43). Thousand Oaks, California: Corwin Press.

[10] Disinger, J.F. (2005). Environmental education's definition problem. In H.R. Hungerford, W.J. Bluhm, T.L. Volk \& J.M. Ramsey (Eds.), Essential readings in environmental education, 3ed. (pp. 17-28). Champaign, IL: Stipe Publishing.

[11] EarthCARE ${ }^{\mathrm{TM}}$ (2009). An environmental education partnership. 2008/2009 year-end report for the Ottawa-Carleton District School Board. AUTHOR. Retrieved from http://www.earthcarecanada.com/library/OCDSBreport09.pdf

[12] EarthCARE ${ }^{\mathrm{TM}}$ An Environmental Education Partnership. (2010). Retrieved from http://www.earthcarecanada.com/EarthCARE_Program/default.asp

[13] Firth, M. (2010, November 18). Eco-clubs make the grade with Green. The Tribune. Retrieved from http://www.wellandtribune.ca/ArticleDisplay.aspx?e=2851755

[14] Hart, P. (1996). Problematizing enquiring in environmental education: Issues of method in a study of teacher thinking and practice. Canadian Journal of Environmental Education, 1, 56-88.

[15] Hart, P. \& Nolan, K. (1999). A critical analysis of research in environmental education. Studies in Science Education, 34(1), 169.

[16] Hsu, S. \& Roth, R.E. (1999). Predicting Taiwanese secondary teachers' responsible environmental behavior through environmental literacy variables. Journal of Environmental Education, 30(4), 11-19.

[17] Hungerford, H., Peyton, R.B., \& Wilke, R.J. (2005). Goals for curriculum development in environmental education. The Journal of Environmental Education, 11(3), 42-47.

[18] Kollmuss, A. \& Agyeman, J. (2002). Mind the gap: Why do people act environmentally and what are the barriers to proenvironmental behavior? Environmental Education Research, 8(3), 239-260.

[19] Marcinkowski, T. (1997). Assessment in environmental education. In R.J. Wilke (ed.), Environmental education teacher resource handbook: A practical guide for K-12 environmental education (pp.143-197). Thousand Oaks: Corwin Press

[20] McBeth, W.C. (1997). An historical description of the development of an instrument to assess the environmental literacy of middle school students. (Doctoral dissertation, Southern Illinois University). Retrieved from http://proquest.umi.com.ezproxy.uwindsor.ca/pqdweb?RQT=500\& pageName=diss_copyright.vtp

[21] McBeth, B., Hungerford, H., Marcinkowski, T., Volk, T., \& Meyers, R. (2008). National Environmental Literacy Assessment Project: Year 1, National Baseline Study of Middle Grades Students Final Research Report. Retrieved from http://www.epa.gov/education/pdf/MASTERNELA_Year1Report_ 081208_.pdf

[22] McBeth, W. \& Volk, T.L. (2010). The national environmental literacy project: A baseline study of middle grade students in United States. The Journal of Environmental Education, 41(1), 5567. doi: 10.1080/0095890903210031
[23] Milfont, T.L. \& Duckitt, J. (2010). The environmental attitudes inventory: A valid and reliable measure to assess the structure of environmental attitudes. Journal of Environmental Psychology, 30, 84-94.

[24] Morrone, M., Manci, K., \& Carr, K. (2001). Development of a Metric to Test Group Differences in Ecological Knowledge as One Component of Environmental Literacy. Journal of Environmental Education, 32(4), 33. Retrieved from Academic Search Complete database.

[25] Muijs, D. (2004). Doing quantitative research in education with SPSS. London: Sage Publications.

[26] North American Association for Environmental Education. (2004). Environmental education materials: Guidelines for excellence. Rock Spring, GA: NAAEE. Retrieved from http://www.naaee.org/npeee/materials.php

[27]Ontario EcoSchools. (2010). Retrieved from http://www.ontarioecoschools.org/index.html

[28] Ontario Ministry of Education News Release (February 2009). Making education greener: McGuinty Government promotes environmental education in schools. Retrieved from http://www.edu.gov.on.ca/eng/document/nr/09.02/nr0226.html

[29] Ontario Ministry of Education. (2009). Acting today, shaping tomorrow: A policy framework for environmental education in Ontario schools. Author.

[30] Puk, T. \& Behm, D. (2003). The diluted curriculum: The role of government in developing ecological literacy as the first imperative in Ontario secondary schools. Canadian Journal of Environmental Education, 8, 217-236.

[31] Raven, P.H. \& Berg, L. R. (2006). Environment. $5^{\text {th }}$ ed. Danver, MA: John Willey.

[32] Roberts, N.S. (2008). Impacts of a national green corps program (Eco-Clubs) on students in Indian and their participation in environmental education activities. Environmental Education Research, 15(4), 443-464.

[33] Roth, C.E. (1992). Environmental Literacy: Its roots, evolution, and directions in the 1990s. Columbus, OH: ERIC Clearinghouse for Science, Mathematics, and Environmental Education. $\quad$ Retrieved from http://www.eric.ed.gov/PDFS/ED348235.pdf

[34] Rovira, M. (2000). Environmental education programmes: Some issues and problems. Environmental education research, 6(2), 143-155.

[35] Ruiz-Mallen, I., Barraza, L., Bodenhorn, B., \& Reyes-Garcia, V. (2009). Evaluating the impact of an environmental education programme: An empirical study in Mexico. Environmental Education Research, 371-387. doi:10.1080/13504620902906766.

[36] Russell, C.L., Bell, A.C. and Fawcett, L. (2000). Navigating the waters of Canadian environmental education. In T. Goldstein \& D. Selby (Eds). Weaving connections: Educating for peace, social and environmental justice (pp.196-217). Toronto: Sumach Press.

[37] Smith, D. (2010, October 29). Halton's EcoSchool program thriving: Environmental program has grown from four to 99 schools since 2006. InsideHalton.com. Retrieved from http://www.insidehalton.com/community/environment/article/8957 99

[38] Stapp, W.B. et al. (2005). The concept of environmental education. In H.R. Hungerford, W.J. Bluhm, T.L. Volk \& J.M. 
Ramsey (Eds.), Essential readings in environmental education, 3ed. (pp. 33-36). Champaign, IL: Stipe Publishing.

[39] Swanepoel, C.H., Loubser, C.P., \& Chacko, C.P.C. (2002). Measuring the environmental literacy of teachers. South African Journal of Education, 22(4), 282-285.

[40] UNESCO. (1978). Final report: Intergovernmental conference on environmental education. Organized by UNESCO in cooperation with UNEP, Tbilisi, USSR, 14-26 October 1977.

[41] UNESCO-UNEP International Environmental Education Programme. (1983). Trends, needs and priorities in environmental education since the Tbilisi conference: An Overview (Preliminary report of a world survey). Environmental Educational Series 1, AUTHOR.

[42] Volk, T.L. \& McBeth, W. (2005). Environmental literacy in the United States. In H.R. Hungerford, W.J. Bluhm, T.L. Volk \& J.M. Ramsey (Eds.), Essential readings in environmental education, 3ed. (pp. 73-86). Champaign, IL: Stipe Publishing.

[43] Walsh-Daneshmandi, A., \& MacLachlan, M. (2006). Toward effective evaluation of environmental education: Validity of the children's environmental attitudes and knowledge scale using data from a sample of Irish adolescents. Journal of Environmental Education, 37(2), 13-23. Retrieved from Academic Search Complete database.

[44] Wang, S.M. (2009). The development of performance evaluation for green schools in Taiwan. Applied Environmental Education and Communication, 8(1), 49-58. doi:10.1080/15330150902953498

[45] Working Group on Environmental Education. (2007, June). Shaping our schools, shaping our future: Environmental education in Ontario schools. Report of the Working Group on Environmental Education. Ontario: Ontario Ministry of Education. 